\title{
Tendências em pesquisas sobre bibliotecas universitárias: um estudo bibliométrico dos anais do SNBU
}

\author{
Mateus Rebouças Nascimento \\ Mestrando; Universidade Federal de Santa Catarina, Florianópolis, SC, Brasil; \\ maateusreboucas@gmail.com; ORCID: https://orcid.org/0000-0001-9211-327X \\ Danielly Oliveira Inomata \\ Doutora; Universidade Federal do Amazonas, Manaus, AM, Brasil; \\ inomata.danielly@gmail.com; ORCID: https://orcid.org/0000-0001-5657-2137 \\ Célia Regina Simonetti Barbalho \\ Doutora; Universidade Federal do Amazonas, Manaus, AM, Brasil; \\ celia.simonetti@gmail.com; ORCID: https://orcid.org/0000-0002-4657-9156 \\ Cleiton Mota de Souza \\ Mestre; Universidade Federal do Amazonas, Manaus, AM, Brasil; \\ cleiton.mota.s@gmail.com; ORCID: https://orcid.org/0000-0003-1535-7240
}

\begin{abstract}
Resumo: Discute as tendências em pesquisas sobre bibliotecas universitárias por meio da análise bibliométrica dos anais do Seminário Nacional de Bibliotecas Universitárias (SNBU). Justifica-se a pesquisa a partir da necessidade de dimensionar as temáticas expostas no maior evento sobre bibliotecas universitárias, que despontam para as tendências das pesquisas, no Brasil. Foram utilizados como fonte de informação os anais do SNBU disponibilizados na rede em meio eletrônico, cuja extração dos metadados permitiu a análise das palavras-chave indexadas pelos autores nos artigos, padronizados em seguida de acordo com as especificações do software métrico VOSviewer. Conclui-se que os temas mais tratados no seminário são relacionados às tecnologias emergentes nas bibliotecas, assim como a produção científica e suas vertentes, envolvendo a questão da comunicação e os repositórios que permeiam esse processo, inferindo que as discussões sobre bibliotecas universitárias evoluem conforme o advento das tecnologias de informação e comunicação.
\end{abstract}

Palavras-chave: Bibliometria; Bibliotecas universitárias; Análise temática; Seminário Nacional de Bibliotecas Universitárias

\section{Introdução}

Na Sociedade da Informação, a produção do conhecimento perpassa diversos contextos, existindo a necessidade de discutir processos que permeiam e 
prospectam seu desenvolvimento por intermédio dos estudos métricos da informação, investigado por pesquisadores da Ciência da Informação e áreas correlacionadas.

Com o desenvolvimento da ciência, emergiram estudos quantitativos na área da informação para verificar a evolução dessas produções, a partir das métricas que "[...] possibilitam a análise dos conhecimentos produzidos gerando indicadores utilizados para mensurá-los, proporcionando para ciência a verificação do que está sendo produzido, prospectando e contribuindo para o avanço do conhecimento.” (NASCIMENTO; PINTO; DIAS, 2020, p. 209).

Camargo e Barbosa (2018) destacam que são poucos os estudos que utilizam técnicas para medir o desempenho de temas ou áreas temáticas, citando os estudos de Cobo et al. (2011), Hayashi e Leta (2013). No entanto, os estudos que avaliam o conhecimento produzido por meio das métricas, contribuindo e prospectando a ciência no meio acadêmico a partir de seus produtos, segundo Urbizagastegui e Restrepo-Arango (2017) vêm crescendo exponencialmente no Brasil, com aplicações em diversos cenários.

A produção de artigos como produto de divulgação da ciência envolve previamente o conhecimento do que já foi gerado de modo a constituir elementos para a composição de novas descobertas a partir dos saberes existentes, os quais irão alimentar novos ciclos de produção do conhecimento. Nesta perspectiva, considera-se que conhecer é incorporar um conceito novo ou original, sobre um acontecimento ou fenômeno qualquer.

Sendo assim, o conhecimento não nasce do vazio e sim das experiências acumuladas no cotidiano das pessoas, por intermédio de experimentos, dos relacionamentos interpessoais, das leituras de livros e artigos publicados em diversos canais da ciência, como congressos, sociedades científicas, protocolos de colaboração, formando assim redes de relacionamento, com objetivo de disseminar o que é produzido e objeto de estudo de diversas métricas da informação.

A produção do conhecimento objetiva comunicar o saber e mantê-lo disponível para o uso em pesquisas futuras por outros pesquisadores, sendo passível de gerar novos conhecimentos no âmbito científico, tecnológico, 
cultural e social para consolidar temáticas amplamente discutidas por meio da comunicação efetiva da ciência.

Nesse contexto ambientado na ciência, a comunicação científica é entendida como o intercâmbio de informações entre membros de determinada comunidade, sendo a “[...] transferência de informações científicas, tecnológicas ou associadas a inovações e que se destinam aos especialistas em determinadas áreas do conhecimento." (BUENO, 2010, p. 2).

No Brasil, as bibliotecas universitárias são estudadas por pesquisadores que disseminam suas pesquisas especialmente no Seminário Nacional de Bibliotecas Universitárias (SNBU), evento científico, profissional, tecnológico e cultural. $\mathrm{O}$ evento ocorre periodicamente a cada dois anos, em locais diferentes do país, e discute temáticas inerentes a essa tipologia de unidades de informação, sendo o maior evento brasileiro no âmbito de bibliotecas universitárias e o principal fórum nacional de discussão, atualização e aperfeiçoamento nesta área específica, cuja primeira edição ocorreu em 1978.

Diante dessa perspectiva, o artigo objetivou analisar as tendências em pesquisas sobre bibliotecas universitárias, por meio de um estudo bibliométrico das comunicações publicadas nos anais do SNBU durante seus 40 anos. Nesse sentido, é apresentado o mapeamento da produção de conhecimento sobre bibliotecas universitárias, identificando as tendências em pesquisa, destacando assim indicadores bibliométricos sobre as temáticas discutidas no âmbito das bibliotecas universitárias brasileiras.

\section{A produção de artigos como produto da ciência}

A ciência se constrói por meio da produção de pesquisadores que disseminam o conhecimento investigado em diversos formatos, como artigos, dissertações, teses, capítulos de livros, apresentação em eventos científicos, dentre outras formas de publicizar o saber, compreendendo que um novo conhecimento é sempre oriundo de conhecimentos anteriores (MERTON, 1979).

O desenvolvimento da ciência ocorre por intermédio dessa produção no ato de criação e geração de conhecimento. Ferreira e Silva (2011, p. 2) sinalizam que: 
A produção científica é onde a sociedade e organizações podem retirar conhecimentos para a melhoria de suas práticas e processos, o que pode justificar a elaboração deste trabalho, justificado também pela possibilidade dos gestores de instituições acadêmicas, entenderem através das respostas dos alunos pesquisados, pontos que podem ser trabalhados para um aumento quantitativo e melhoria qualitativa das produções científicas dos discentes, alavancando a criação do conhecimento através da pesquisa.

Nesse contexto, Hayashi e Guimarães (2016, p. 161) destacam que na ciência, "[...] a construção do conhecimento científico é um processo social que ocorre a partir de resultados anteriores, viabilizado por meio de processos de comunicação científica.”. Esse processo deve ser permeado pela divulgação e comunicação dos resultados de pesquisa para colaborar com o entendimento do fenômeno estudado bem como com a construção de novos saberes.

A comunicação científica consiste, no processo citado pelas autoras, de troca de ideias e informações entre pesquisadores por meio de seus estudos científicos. Para entender e efetivar a produção de artigos como produto da ciência é necessário compreendê-lo como propõe - Garvey (1979, p. 10):

[...] espectro total de atividades informacionais que ocorrem entre os produtores de informação científica, desde o momento em que eles iniciam suas pesquisas até a publicação de seus resultados e sua aceitação e integração a um corpo de conhecimento.

De fato, como destaca o autor, o conhecimento produzido por pesquisadores, registrado em produções científicas, contribui com o processo de comunicação especialmente quando publicado em forma de artigos os quais constituem canais comunicativos dinâmicos da ciência, tendo em vista que se trata de:

[...] conjunto de esforços, facilidades, processos dinâmicos e complexos, consensual e socialmente compartilhados, por meio dos quais o conhecimento científico - em sua vertente tácita e explícita - é criado, compartilhado e utilizado. (LEITE; COSTA, 2007, p. 93).

Vistos da forma como retratam os autores, os artigos científicos colaboram para realização de estudos no campo da Ciência da Informação, a qual que investiga temas específicos, por meio de métricas, tornando possível mensurar o que é comunicado na ciência a partir de seus produtos, impactando diretamente na consolidação do conhecimento. 


\section{Bibliometria: conceitos e aplicações}

Os estudos bibliométricos são efetivados na Ciência da Informação em função do "[...] papel relevante na análise da produção científica de um país, uma vez que seus indicadores podem retratar o comportamento e desenvolvimento de uma área do conhecimento.” (ARAÚJO; ALVARENGA, 2011, p. 52). Pode-se inferir, assim, que por meio da bibliometria é possível mensurar o conhecimento contido em diversos meios comunicativos da ciência, prospectando e consolidando saberes científicos.

Nesse contexto, com foco no ambiente universitário, Vanz, Santin e Pavão (2020, p. 22) destacam que a aplicação de métricas consiste em "[...] subsídios importantes para a gestão, o planejamento e a avaliação das universidades, permitindo o acompanhamento e a verificação do cumprimento de objetivos institucionais.".

Corroborando com as assertivas dos autores, Mattedi e Spiess (2017, p. 633-634) destacam que os “[...] indicadores quantitativos não são apenas produtos científicos, mas constituem também instrumentos para avaliação, regulação e formulação de políticas”. Os autores consideram ainda que a aplicação de indicadores para avaliação se conforma em três unidades de análise da atividade científica:

a) micro (pesquisadores);

b) meso (periódicos);

c) macro (organizações), sendo os estudos caracterizados por seu escopo multidisciplinar.

Quanto a sua origem, Figueiredo (1977) explicita que o estudo bibliométrico é marcado na Ciência da Informação por uma dupla preocupação: a análise da produção científica e a busca de benefícios práticos imediatos para o cenário das bibliotecas, com foco no desenvolvimento de coleções e gestão de serviços bibliotecários, retificando os argumentos expostos por Vanz, Santin e Pavão (2020), bem como por Mattedi e Spiess (2017).

Nesse contexto, os estudos métricos são constituídos para dimensionar e analisar as temáticas mais discutidas, “[...] propiciando diferentes ramificações e 
abordagens de análise, com objetos, finalidades e contextos diversos, que podem adotar uma variedade de técnicas e métodos de pesquisa." (CURTY; DELBIANCO, 2020, p. 5).

As análises inferidas pelas métricas por meio de suas inter-relações, na prática, contextualizam a ciência em indicadores, como os destacados por Noronha e Maricato (2008):

[...] análise de citação, cujos dados permitem descobrir: elite da pesquisa (autores mais produtivos); frente de pesquisa; fator de impacto dos autores e dos periódicos; tipos de documentos citados; vida média da literatura e obsolescência da literatura citada; sociabilidade dos autores (procedência geográfica e institucional dos autores); entre outros.

Com esses indicadores apresentados pelos autores, é possível inferir que as temáticas também acompanham o desenvolvimento da ciência, disseminando informações que destacam e revelam aspectos fundamentais para a consolidação do conhecimento científico produzido por instituições de ensino superior e centros de pesquisa, sendo proeminente para enfatizar a comunicação científica e os produtos da ciência.

As pesquisas aplicadas que utilizam estudos bibliométricos discutem questões que permeiam diversos cenários, como a produtividade, por exemplo, foco dos trabalhos de Oliveira e Gracio (2011). As autoras analisam os pesquisadores mais produtivos no tema estudos métricos por meio da base Scopus e calculam o coeficiente de correlação e equação de regressão do índice h, em função do total de citações extraídas na base analisada.

Além da produtividade, aplicações relacionadas à coautoria entre atores da ciência são explicitadas por Vanz (2013) em um de seus estudos, utilizando a teoria das redes na aplicação bibliométrica para apresentar medidas mais efetivas para redes de coautoria, como densidade e medidas de centralidade. Essa aplicação destaca a colaboração de redes colaborativas no ambiente científico, compreendendo que elas fundamentam as relações que existem na ciência.

As aplicações dos estudos bibliométricos permeiam o uso de diversas bases estruturadas como Scopus e Web of Science, bem como a análise de dados 
não estruturados. Almeida e Gracio (2019) utilizaram essas bases para analisar a produção científica brasileira sobre o indicador de fator de impacto, por meio de uma revisão de artigos brasileiros publicados, utilizando os preceitos bibliométricos para apresentar a distribuição quantitativa dos artigos em periódicos indexados, assim como a área do conhecimento à qual o periódico está indexado.

Diante o exposto, é possível inferir que os estudos métricos podem ser empregados em diversos contextos onde seja possível o uso de recursos quantitativos como ferramenta de análise. Esses estudos geram indicadores que possibilitam avaliar o crescimento, dispersão, decréscimo, novos interesses que surgem em um contexto como o das bibliotecas universitárias.

\section{Bibliotecas Universitárias}

As bibliotecas, independentemente de sua tipologia, disseminam o conhecimento produzido por pesquisadores por meio de diversos serviços que contribuem com a formação de seus usuários, construindo seres intelectuais e investigativos a partir de seu rico acervo e dos serviços, produtos que disponibilizam.

A biblioteca universitária se caracteriza por sua atuação no contexto da produção de conhecimento científico, uma vez que são entes integrantes de "Instituições de Ensino Superior - IES destinada a suprir as necessidades informacionais da comunidade acadêmica, no desempenho de suas atividades de ensino, pesquisa e extensão.” (CARVALHO, 1981, p. 1).

Ao constituir elementos que ampliam o entendimento do papel da biblioteca universitária na teia orgânica que envolve uma instituição de ensino superior, Lubisco (2014, p. 5) afirma que elas:

[...] por sua natureza, desempenham um papel fundante na instituição à qual estão ligadas, por sua função de partícipes no desenvolvimento dos programas de ensino, pesquisa e extensão e inovação. Essa função se consubstancia na sua atuação como recurso didático-pedagógico (laboratório de aprendizagem); como plataforma de conhecimento (considerando-a fonte de saber e local de registro da produção técnica e científica da instituição); e como fator de estímulo à formação e ao desenvolvimento do espírito científico. 
Como estão ligadas diretamente às IES, como destaca a autora, essa tipologia de biblioteca reveste-se de relevância para a comunidade científica por contribuir com seus produtos e serviços na formação das pessoas que irão se tornar futuros profissionais. Tendo como foco o suporte informacional às atividades de ensino, pesquisa e extensão nessas instituições, a biblioteca universitária apresenta diversas vertentes em sua execução, além de apoiar os processos de inovação recentemente incorporados nesse tripé universitário, em função dos produtos resultantes das pesquisas.

Segundo Lubisco (2011, p. 9), a biblioteca universitária tem de se atualizar, dia após dia, para conseguir manter um espaço adequado tanto para a produção quanto para a disseminação de conhecimento. Reforçando esta linha de raciocínio, a autora complementa afirmando que:

O equilíbrio desejado entre a disponibilidade e o acesso à informação, as necessidades e exigências dos usuários e os meios necessários à facilitação deste equilíbrio fazem da gestão dessas bibliotecas um processo instigante e desafiador (LUBISCO, 2011, p. 9).

Na busca do equilíbrio destacado pela autora, Otlet (1989) destaca que em relação ao seu público-alvo, uma biblioteca universitária se destina aos estudantes, aos professores, aos especialistas e aos pesquisadores. Conhecendo o seu público, é possível prestar serviços diretamente com base nos objetivos propostos pela instituição mantenedora.

Tendo em vista o desenvolvimento constante das bibliotecas universitárias em diversos aspectos, bem como o entendimento do público a ser atendido, ao bibliotecário compete acompanhar este processo considerando que:

As bibliotecas, como o mundo todo, estão passando por transformações. A informação deve ser confiável, resultando assim em conhecimento. Hoje, o tempo de espera para se obter uma informação não pode ser comparado ao tempo em que não existiam suportes necessários à recuperação da informação. $\mathrm{O}$ papel do bibliotecário neste mundo não é mais o de guardador de acervos, mas o de um profissional que encontrará a informação desejada no momento certo, contribuindo decisivamente com o processo de transformação da informação em conhecimento. (LEITÃ̃, 2005, p. 24). 
Com a visão de que as bibliotecas universitárias são organizações em constante evolução, segundo uma das leis de Ranganathan, estudos relacionados a elas surgiram na literatura, perpassando vertentes que contribuem com a melhor oferta de serviços para seus usuários, tratando sobre temáticas que relacionam o contexto vivido, publicizadas em canais comunicativos da ciência.

No Brasil, esses estudos são disseminados principalmente no SNBU, evento nacional, já citado, que ocorre periodicamente a cada dois anos em locais diferentes e discute temáticas inerentes às bibliotecas universitárias, possibilitando momentos de reflexão e o constante avanço no conjunto de conhecimentos produzidos para qualificar a ação desses agentes informacionais.

\section{Procedimentos metodológicos}

Esta pesquisa caracteriza-se, quanto aos seus objetivos, como exploratória e descritiva, tendo em vista que busca explorar, descobrir ideias e inferências, na expectativa de adquirir maior familiaridade com o fenômeno pesquisado (SELLTIZ et al.,1965), além de descrever com exatidão os fatos e fenômenos de determinada realidade (FIGUEIREDO, 2008, p. 94). Quanto à abordagem do problema, trata-se de uma pesquisa quantitativa, tendo como procedimentos técnicos os preceitos bibliométricos.

A coleta dos dados foi realizada no período de outubro de 2019 a janeiro de 2020 nos anais do SNBU disponíveis no Repositório Institucional da Universidade Federal de Minas Gerais $(\mathrm{UFMG})^{1}$, bem como no portal da Federação Brasileira de Associações de Bibliotecários, Cientistas de Informação e Instituições $(\mathrm{FEBAB})^{2}$, que dispõe dos documentos referentes às edições de 2016 e 2018 digitalizadas.

A pesquisa considerou um recorte temporal de 40 anos, entre 1978 e 2018, exceto 1983 em função da impossibilidade de acesso aos anais. Sendo assim, o universo da pesquisa totalizou os trabalhos apresentados no evento, sendo a amostra composta por 2.788 artigos disponibilizados para serem analisadas as temáticas discutidas pelos pesquisadores.

O fluxo metodológico adotado na pesquisa foi constituído em sete etapas conforme disposto na Figura 1, compreendendo a sistemática deste estudo 


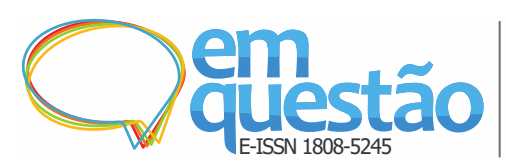

Tendências em pesquisas sobre bibliotecas universitárias: um estudo bibliométrico dos anais do do SNBU

Mateus Rebouças Nascimento, Danielly Oliveira Inomata, Célia Regina Simonetti Barbalho, Cleiton Mota de Souza

bibliométrico por meio da identificação, padronização, composição, coleta, análise, geração e apreciação do que foi analisado no período estabelecido.

Figura 1 - Fluxo de etapas metodológicas da pesquisa



Fonte: Elaborado pelos autores (2021).

Para realizar o mapeamento da produção de conhecimento sobre bibliotecas universitárias, nas primeiras etapas metodológicas foram identificados e coletados individualmente de cada artigo os respectivos descritores: autor(es), título, filiação, resumo e palavras-chave. Os descritores foram inseridos em planilha com os dados separados por ponto e vírgula, utilizando tabulações compatíveis com o software VOSviewer ${ }^{3}$, com cada descritor distribuído em colunas respectivas na sequência mencionada anteriormente.

Após essa etapa de coleta e padronização, houve o processamento dos dados conforme as especificações mencionadas do software VOSviewer, ferramenta desenvolvida por Nees Jan van Eck e Ludo Waltman, da Leiden University, na Holanda, permitindo fazer análises por meio de relações de coocorrência, cocitação e mapas de rede.

A escolha do programa ocorreu considerando o quantitativo de dados que foram extraídos dos anais do evento, bem como as variáveis a serem analisadas, além da possibilidade de utilizar a ferramenta para inserir descritores padronizados para geração de indicadores bibliométricos de diversas temáticas do conhecimento.

Quanto ao software VOSviewer, a ferramenta utiliza-se um método de visualização baseado na distância entre os nós da rede analisada, de modo que a 
distância entre dois nós indica aproximadamente a intensidade da relação entre eles, sendo tal relação tão maior quanto menor for a distância (VAN ECK; WALTMAN, 2014).

Por meio desta ferramenta, é possível extrair informações de base de $\operatorname{dados}^{4}$ estruturadas como a Web of Science, por exemplo, para gerar redes métricas, tendo a possibilidade de apresentar indicadores que explicitam as temáticas mais discutidas em diversas áreas do conhecimento, os principais atores no cenário analisado, dentre outros fatores.

A apreciação crítica dos resultados foi efetuada a partir da análise dos grafos gerados pelo software, considerando os nós e as arestas produzidas para: autor, filiação e palavras-chave. Ademais, destaca-se que foi utilizado na apresentação dos resultados o mapa de calor, que consiste na representação gráfica de maior incidência de determinada temática, a partir da coloração no mapa.

Com base no corpus selecionado para análise, foram identificadas as tendências em pesquisas sobre bibliotecas universitárias, possibilitando compor um quadro dos temas discutidos nos últimos 40 anos do maior evento sobre a temática da América Latina.

\section{Resultados e Discussão}

Os resultados analisados na pesquisa bibliométrica estão expostos com o intuito de dimensionar inferências relacionadas às temáticas mais discutidas sobre bibliotecas universitárias no contexto do SNBU, além da distribuição temporal dos artigos publicados no evento, dentre outros indicadores.

A Figura 2 apresenta a distribuição temporal dos trabalhos publicados nos anais do SNBU no período de 1978 a 2018. Nota-se que em suas primeiras edições, o evento recebeu um número menor de artigos, mantendo-se nas décadas de 1980 e 1990 na mesma intensidade, evidenciando a trajetória do evento, especialmente quanto ao fortalecimento de sua popularidade com o passar dos anos. 
Figura 2 - Distribuição temporal dos trabalhos publicizados no evento

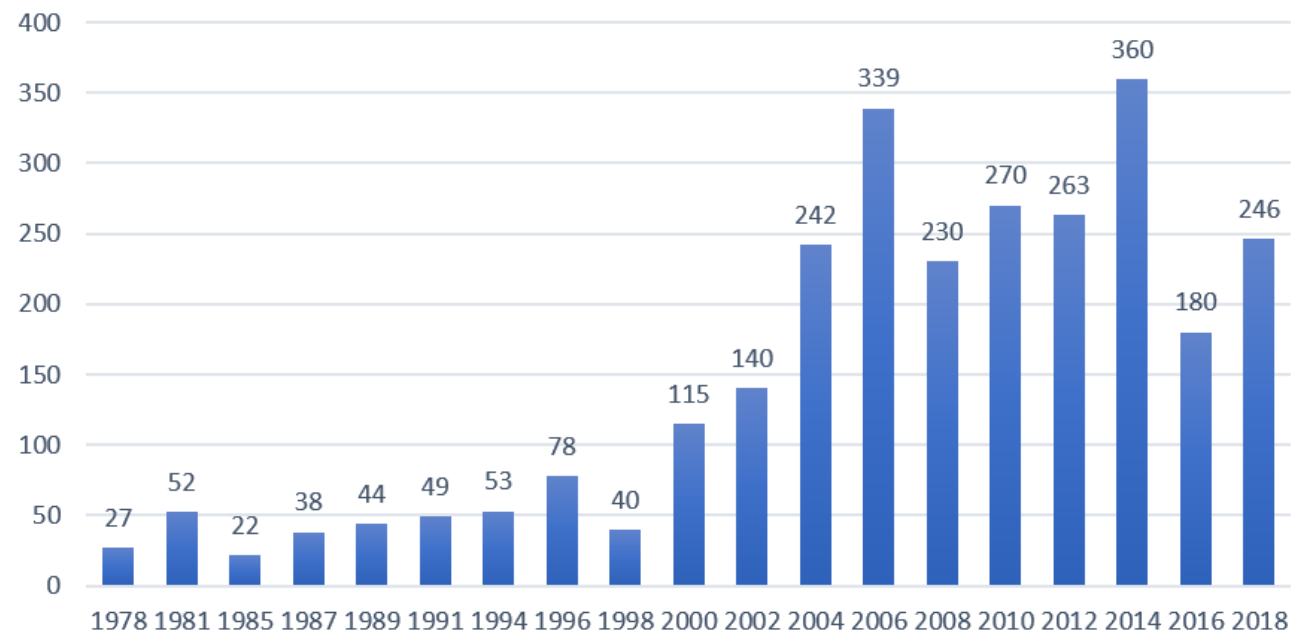

Fonte: Elaborado pelos autores (2021).

A partir dos anos 2000, verifica-se um crescimento no número de comunicações apresentadas, o que denota que o evento passou a contar com o apoio e a adesão por parte dos bibliotecários e profissionais da área de Ciência da Informação, concentrando esforços em compartilhar o resultado de investigações sobre temáticas emergentes no contexto das bibliotecas universitárias no SNBU.

Observa-se que esse crescimento acompanha o aumento dos cursos de pós-graduação em Ciência da Informação no Brasil, tendo em vista que o surgimento do primeiro doutorado em Ciência da Informação foi na década de 1990 e que, a partir de 2000, ocorreu o fortalecimento dos programas de pósgraduação no país (SOUZA; STUMPF, 2009, p. 49), o que pode ter contribuído para a elevação do quantitativo de trabalhos expostos no evento, refletindo no aumento da produção científica da área como um todo.

Ademais, verifica-se que a consolidação do Seminário Nacional de Bibliotecas Universitárias como um renomado evento, com constância de periodicidade bienal, permitiu que os atores envolvidos com a temática tivessem um espaço científico, profissional, tecnológico e cultural profícuo para o compartilhamento de conhecimentos sobre bibliotecas universitárias e temas afins, estabelecendo assim o evento como um importante canal comunicativo da área para a divulgação de saberes, ao mesmo tempo em que se tornou um ambiente para reflexões. 
Em relação à análise temática das pesquisas expostas no Seminário, a Figura 3 explicita o mapa do conhecimento publicizado conforme as palavraschave indexadas pelos próprios autores nos artigos coletados. É necessário observar que o tamanho dos nós (círculos), em cada um dos mapas, diz respeito ao quantitativo de documentos que determinado item possui, critério esse préestabelecido pelo software VOSviewer, ressaltando-se que, a contagem de termos se pautou na existência de, pelo menos, três ocorrências das palavraschave.

Figura 3 - Mapa de conhecimento de acordo com as palavras-chave dos artigos.

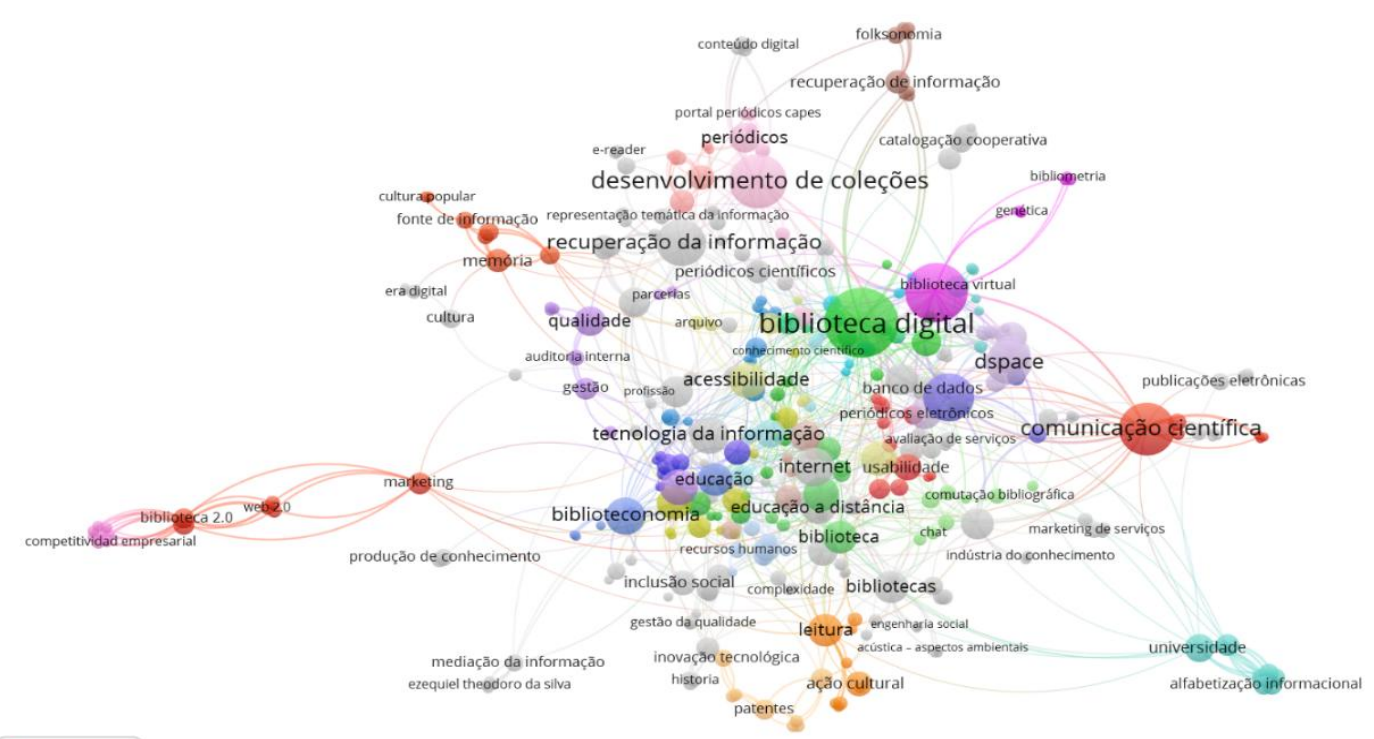

\& vosviewer

Fonte: Elaborado pelos autores (2021).

Observa-se que as temáticas tecnológicas se destacam no mapa, tendo em vista que as tecnologias da informação e comunicação (TIC) permearam o trabalho executado pelas bibliotecas universitárias nos últimos anos, sendo amplamente estudadas por pesquisadores da área em caráter profissional e tecnológico, concentrando esforços para efetivar a eficácia da prestação de serviços com foco em seus usuários.

O tema "biblioteca digital" apresenta o maior agrupamento no mapa (cluster), contando com o maior número de ocorrências: indexadas 74 vezes pelos autores. As temáticas "produção científica" (58 ocorrências), 
"desenvolvimento de coleções" (51 ocorrências), "comunicação científica" (49 ocorrências) e "repositório institucional" (42 ocorrências) sucedem em ordem consecutiva.

Nota-se a relação de diversos termos com assuntos em comum como "desenvolvimento de coleções", que está interligado diretamente com os termos "periódicos", "portal de periódicos Capes", "representação temática da informação", dentre outros. É válido também destacar o cluster "comunicação científica", como processo neste meio de comunicar a ciência encontrou respaldo no uso de publicações eletrônicas e a plataforma DSpace na disseminação em repositórios, os quais compõem a esfera de competências das bibliotecas universitárias

Observou-se que as atividades e processos que envolvem o trabalho das bibliotecas relacionados às coleções e à produção do conhecimento, por exemplo, são algumas das preocupações dos pesquisadores da área, refletindo nas investigações que tratam sobre desenvolvimento, aquisição e seleção de coleções, assim como nas questões que permeiam os portais de periódicos, acervos digitais, repositórios, dentre outros.

Com relação aos termos indexados pelos autores nos artigos científicos, é possível expor ainda que eles revelam a predominância dos assuntos relacionados a diversas vertentes das bibliotecas universitárias nos seguintes aspectos: no modo de recuperar a informação, na forma de comunicar cientificamente, no uso das tecnologias digitais, para além de desenvolver suas coleções por meio de periódicos, bases de dados, livros, dentre outros.

Ao analisar as temáticas explicitadas, é notório destacar a evolução das discussões sobre o trabalho executado pelas bibliotecas universitárias, tendo em vista que nas primeiras edições do SNBU a temática predominante era sobre automação em bibliotecas, com base nos pressupostos iniciais, viabilizando a discussão em torno de questões relacionadas à aquisição, catalogação, dentre outras técnicas. Na atualidade, é perceptível que temas emergentes às tecnologias se destacam nas comunicações expostas no seminário.

Conforme apontou Ramalho (1993, p. 57), as tecnologias da informação se concretizam como “[...] elemento de dinamismo da biblioteca, poderão 
Mateus Rebouças Nascimento, Danielly Oliveira Inomata, Célia Regina Simonetti Barbalho, Cleiton Mota de Souza

garantir a sua existência como instrumento vivo, funcional e atualizado, enfim "moderno"'. No entanto, observa-se que desde a década de 1990, as tecnologias da informação estão efetivamente presentes nas discussões sobre bibliotecas universitárias, como demonstra a Figura 3.

Com objetivo de analisar minuciosamente as temáticas abordadas pelos participantes do SNBU, a Figura 4 compila as mesmas informações utilizadas nos mapas de conhecimento, destacando um mapa de calor das questões mais examinadas. O pressuposto de que quanto mais vermelha é a área, maior é a zona de concentração de esforços de publicações nesse ponto do mapa.

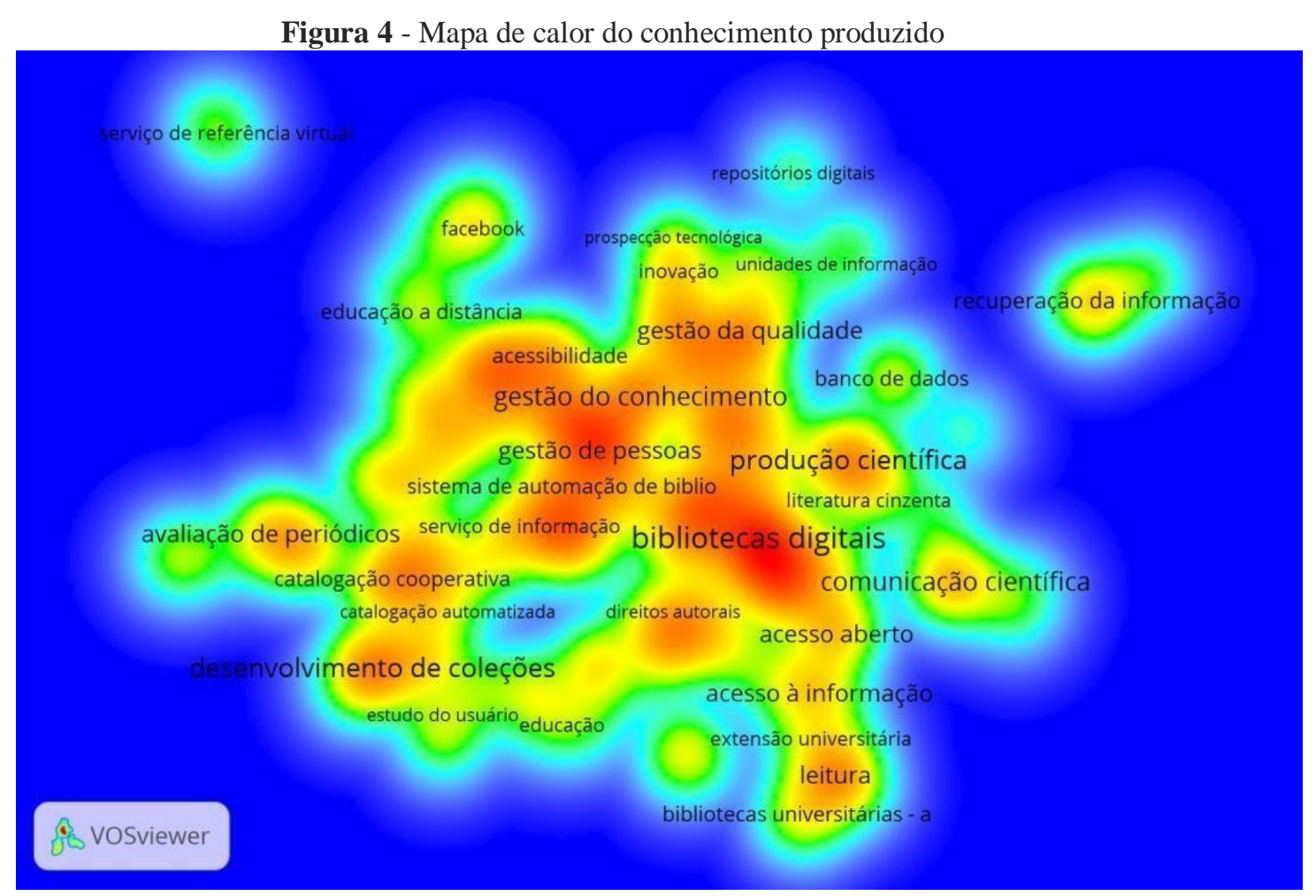

Fonte: Elaborado pelos autores (2021).

Nesta perspectiva, verifica-se no mapa de calor que os campos onde os termos "bibliotecas digitais", "gestão do conhecimento", "gestão de pessoas" e "produção científica" são os que possuem a coloração mais vermelha, isto significando que esses são os temas abordados com maior ocorrência durante o período analisado por meio dos termos indexados a partir do vocabulário controlado elaborado.

A Gestão do Conhecimento (GC), conforme destacada a sua intensidade, apresenta-se como uma temática muito utilizada em bibliotecas universitárias, 
sendo estratégico no ambiente organizacional, visando ao "[...] alcance dos objetivos e de vantagem competitiva no mercado por meio dos conhecimentos adquiridos com esta prática.” (BARBALHO; NASCIMENTO, 2019, p. 67).

Quanto aos termos com menor coloração vermelha, infere-se que eles não possuem a maior ocorrência como: recuperação da informação, serviço de referência virtual, educação, estudo do usuário, dentre outros termos com menor intensidade vermelha no mapa de calor, nos dados de 1978 a 2018. Pode-se inferir que há uma probabilidade dessas ocorrências serem menores em função da evolução das questões que envolvem as atividades relacionadas às bibliotecas universitárias.

A concentração das pesquisas que tratam sobre acesso aberto e acesso à informação sugere no mapa que essas temáticas estão sendo discutidas no contexto atual das bibliotecas universitárias, integrando-se à comunicação científica e expondo trabalhos relacionados aos direitos autorais que permeiam as questões ligadas ao acesso aberto.

A cada edição do SNBU, desde 1978, é definido um tema específico a ser discutido. Uma análise das temáticas das edições, agrupadas pelas décadas da realização do evento, está exposta na Figura 5 com o intuito de destacar a evolução do que foi discutido, expondo os conhecimentos principais de acordo com seus temas.

Figura 5 - Temáticas por décadas
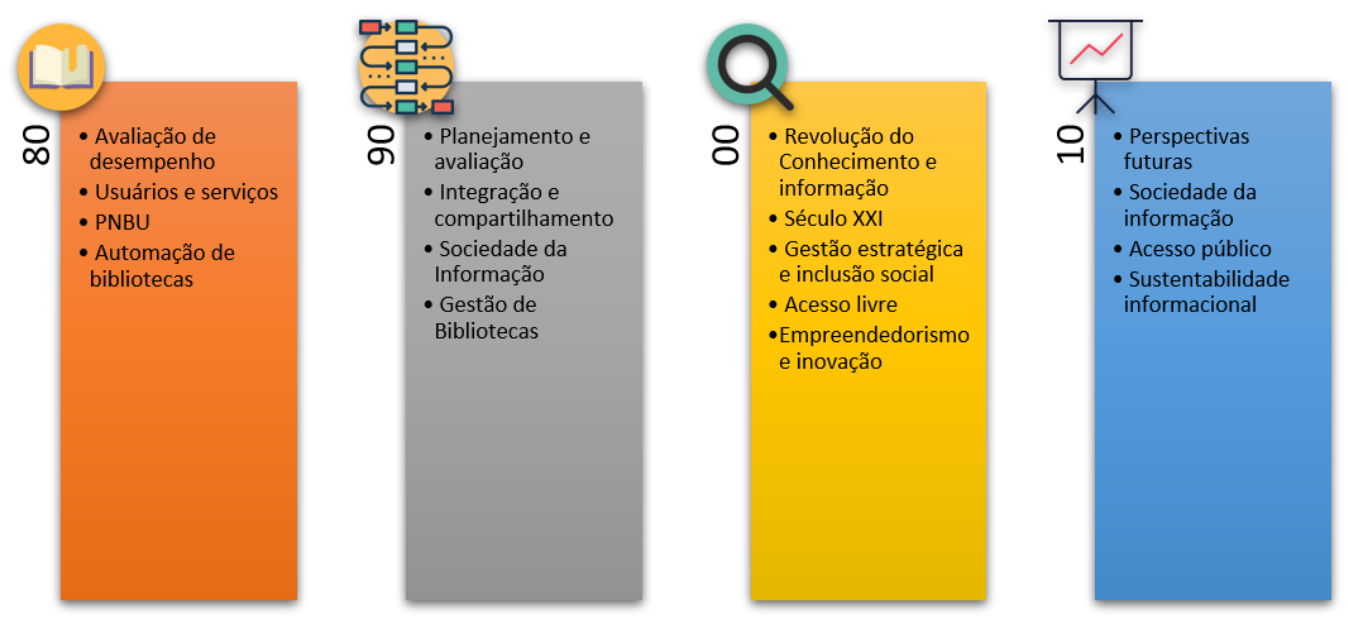

Fonte: Elaborado pelos autores (2021). 
Nas primeiras edições do evento, observa-se que as temáticas tratavam sobre os usuários, serviços, desempenho e a automação das bibliotecas universitárias. Além desses assuntos, o Plano Nacional de Bibliotecas Universitárias (PNBU) foi o tema do SNBU realizado em Porto Alegre, reconhecido como a primeira política pública voltada para bibliotecas universitárias, sendo um marco para a área.

Na década de 1990, observa-se que ações relacionadas à gestão destacaram-se nos temas do evento, onde houve estudos sobre planejamento e avaliação de bibliotecas, assim como a sua gestão, perpassando pela sociedade da informação, caracterizada na época pela intensa convivência com a informação contida em grande parte dos ambientes.

Durante os anos 2000, a revolução do conhecimento e da informação se destacou nos estudos visando a examinar o papel da biblioteca universitária na perspectiva do Século XVI, como espaço para construção do saber na sociedade. As questões sobre a gestão estratégica e inclusão social, assim como o acesso livre à informação, foram discutidas em perpasses no acesso aberto.

Nos últimos anos, são notórios os esforços em pesquisas sobre o futuro da biblioteca universitária, apoiando-se na sustentabilidade, acessibilidade e inclusão informacional dos usuários, refletindo-se essas ações em ensino, pesquisa e extensão, tripé da universidade que sustenta as atividades dessas bibliotecas, ofertando a informação e prestando serviços eficazes.

\section{Considerações finais}

Com base nos objetivos definidos nesta investigação de analisar as tendências em pesquisas sobre bibliotecas universitárias, durante os 40 anos de ocorrência do SNBU, ao investigar o que foi produzido para compreender o que é discutido, pode-se inferir a efetivação das reflexões sobre as bibliotecas universitárias em diversos contextos apresentados.

A produção científica mapeada sobre bibliotecas universitárias destaca que o conhecimento produzido e disseminado nos Seminários Nacionais de Bibliotecas Universitárias evoluiu conforme o amadurecimento dos processos 
contidos nessa tipologia de biblioteca, no intuito de ofertar o melhor para os usuários de bibliotecas.

Partindo deste preceito e dos conhecimentos identificados, mapeados e analisados, pode-se inferir que temáticas relacionadas às tecnologias e à gestão são amplamente utilizadas. A tecnologia evoluiu por meio de plataformas que surgiram para viabilizar uma melhor disseminação do conhecimento de forma abrangente para os usuários, assim como os tipos de gestão voltaram-se para a melhoria dos processos, seja pela qualidade, seja pela gestão dos conhecimentos.

As pesquisas sobre bibliotecas universitárias nos SNBU, assim, foram as pioneiras e contribuíram de forma significativa para se ter a consolidação desses organismos na atualidade, sabendo-se que a ciência se constrói por meio da produção de pesquisadores que publicizam esses conhecimentos, cuja produção contribui efetivamente com a evolução do desempenho das bibliotecas universitárias.

$\mathrm{Na}$ atualidade deste estudo, o contexto em que se discutem pesquisas sobre bibliotecas universitárias permeia questões relacionadas ao acesso aberto, como os repositórios institucionais, os quais permitiram às bibliotecas disseminar a produção do conhecimento das suas respectivas universidades, temática que evoluiu para outros tipos de repositórios já sendo investigados por pesquisadores da área.

A consolidação do Seminário Nacional de Bibliotecas Universitárias nesses 40 anos, como o maior fórum de discussões sobre bibliotecas universitárias da América Latina, permitiu que a temática no Brasil avançasse com a troca de experiências a partir das produções disseminadas a cada dois anos.

Os eventos científicos são canais de comunicação da ciência que permitem que pesquisadores disseminem as suas pesquisas com objetivo de gerar novos conhecimentos, além de divulgar os seus resultados atingidos, como destacado pelos autores Witter e Souza (2007), Ziman (1979), dentre outros, tendo impactos para organismos como as bibliotecas universitárias que possuem um evento específico para discussões. 
Os conhecimentos compartilhados nas edições do SNBU perpassam diversos aspectos ligados às bibliotecas universitárias, desde a formação, aquisição, seleção e desenvolvimento de coleções, o tratamento da informação em si relacionado à catalogação e à indexação, bem como a área de gestão e tecnologias, sendo essa última amplamente discutida na atualidade.

Com o avanço advindo das tecnologias de informação e comunicação, as bibliotecas universitárias modernizaram seus serviços e as temáticas discutidas em pesquisas refletem isto, ofertando para seus usuários a informação com acesso fácil, rápido e gratuito, com tecnologias efetivamente implantadas que evoluem constantemente, visando à melhoria dos serviços ofertados.

Por fim, conclui-se que as bibliotecas universitárias, como tema central, consolidam-se com as temáticas secundárias, tendo como foco sempre o usuário e a prestação de serviços em diversos eixos em que essa tipologia de biblioteca se enquadra, efetivando assim o seu objetivo principal de disseminar a informação precisa para os seus usuários. Tal assertiva se observa a partir dos resultados obtidos com base na análise dos artigos desenvolvidos em pesquisas disseminadas no SNBU.

Como continuidade de pesquisa, sugere-se que sejam investigados de forma aprofundada os artigos publicados na última década do seminário, tendo em vista que essas produções podem direcionar o que será discutido nos próximos anos sobre bibliotecas universitárias, a partir da análise do contexto no qual está inserido este profícuo organismo vivo que é a biblioteca universitária, bem como temas novos pouco estudados denotando um nicho de conhecimento.

\section{Agradecimentos}

Ao professor Fábio Castro Gouveia da Fundação Oswaldo Cruz pelo compartilhamento de conhecimento durante sua vinda a Manaus, contribuindo nas escolhas do percurso metodológico adotado na pesquisa, com a sua disponibilidade em ajudar e a expertise na temática dos estudos métricos da informação, conseguimos consolidar a aplicação dessa investigação. 


\section{Referências}

ALMEIDA, Catia Candida; GRACIO, Maria Claudia Cabrini. Produção científica brasileira sobre o indicador "Fator de Impacto": um estudo nas bases SciELO, Scopus e Web of Science. Encontros Bibli, Florianópolis, v. 24, n. 54, p. 62-77, jan./abr., 2019.

ARAÚJO, Ronaldo Ferreira; ALVARENGA, Lidia A bibliometria na pesquisa científica da pós-graduação brasileira de 1987 a 2007. Encontros Bibli, Florianópolis, v. 16, n. 31, 2011.

BARBALHO, Célia Regina Simonetti; NASCIMENTO, Mateus Rebouças. O mapeamento de redes de relacionamento como estratégia para inovação. In: BARBALHO, Célia Regina Simonetti; BESSA, Zení Silva Jucá; PEREIRA, Sammy Aquino. Gestão da inovação: informação, ação e relações colaborativas. Amazonas: EDUA, 2019.

BUENO, Wilson Costa. Comunicação científica e divulgação científica: aproximações e rupturas conceituais. Informação \& Informação, Londrina, v. 15, n. esp., p. 1-12, 2010.

CAMARGO, Lorena Stephanie de; BARBOSA, Ricardo Rodrigues.

Bibliometria, cienciometria e um possível caminho para a construção de indicadores e mapas da produção científica. Ponto de Acesso, Bahia, v. 12, n. 3, p. 109-125, 2018.

CARVALHO, Maria Carmen Romcy de. Estabelecimento de padrões para bibliotecas universitárias. Fortaleza: UFC, 1981.

COBO, Manuel Jesus et al. Science mapping software tools: review, analysis and cooperative study among tools. Journal of the American Society for Information Science and Technology, New York, v. 62, n. 7, p. 1382-1402, 2011.

CURTY, Renata Gonçalves; DELBIANCO, Natalia Rodrigues. As diferentes metrias dos estudos métricos da informação: evolução epistemológica, interrelações e representações. Encontros Bibli, Florianópolis, v. 25, 2020.

EDIÇÕES ANTERIORES. In: SNBU 2014: XVIII Seminário Nacional de Bibliotecas Universitárias. Belo Horizonte: UFMG, 2014.

FERREIRA, Aurélio Fernando; SILVA, Valéria Bastos da. Produção científica: conceitos, iniciativas e fatores Complicadores. In: ENCONTRO NACIONAL DE ESTUDANTES DE BIBLIOTECONOMIA, DOCUMENTAÇÃO, CIÊNCIA DA INFORMAÇÃO E GESTÃO DA INFORMAÇÃO, 34., 2011, Manaus. Anais [...] Manaus: Universidade Federal do Amazonas, 2011. 
FIGUEIREDO, Nébia Maria Almeida de (org.). Método e metodologia na pesquisa científica. 3. ed. São Caetano do Sul: Yendis Editora, 2008.

FIGUEIREDO, Nice. Tópicos modernos em Bibliometria. Brasília: Associação dos Bibliotecários do Distrito Federal, 1977.

GARVEY, William. Communication: the essence of science. New York: Pergamon, 1979.

HAYASHI, Maria Cristina Piumbato Innocentini; GUIMARÃES, Vera Aparecida Lui. A comunicação da ciência em eventos científicos na visão de pesquisadores. Em Questão, Porto Alegre, v. 22, n. 3, set./dez., 2016.

HAYASHI, Maria Cristina Piumbato Innocentini; LETA, Jacqueline.

Bibliometria e cientometria: reflexões teóricas e interfaces. São Carlos: Pedro e João, 2013.

LEITÃO, Julia Menezelho. Avaliação qualitativa e quantitativa numa biblioteca universitária: grupos de foco. Rio de Janeiro: Interciência, 2005.

LEITE, Fernando César Lima; COSTA, Sely Maria de Souza. Gestão do conhecimento científico: proposta de um modelo conceitual com base em processos de comunicação científica. Ciência da Informação, Brasília, DF, v. 36, n. 1, p. 92-107, jan./abr. 2007.

LUBISCO, Nídia Maria Lienert. Biblioteca universitária: elementos para o planejamento, avaliação e gestão. Salvador: EDUFBA, 2011.

LUBISCO, Nídia Maria Lienert. Relatório de pesquisa: bibliotecas universitárias, seus serviços e produtos: transposição de um modelo teórico de avaliação para um instrumento operacional. Ponto de Acesso, Salvador, v. 8, n. 3, p. 90-141, 2014.

MATTEDI, Marcos Antônio; SPIESS, Maiko Rafael. A avaliação da produtividade científica. História, Ciências, Saúde - Manguinhos, Rio de Janeiro, v. 24, n. 3, jul./set., p. 623-643, 2017.

MERTON, Robert. Os imperativos institucionais da ciência. In: DEUS, Jorge Dias de (org.). A crítica da ciência: sociologia e ideologia da ciência. 2. ed. Rio de Janeiro: Zahar, 1979. p. 37-52.

NASCIMENTO, Mateus Rebouças; PINTO, Adilson Luiz; DIAS, Thiago Magela Rodrigues. Análise da produção intelectual na Pós-Graduação em Ciência da Informação: um estudo bibliométrico baseado em dados da Plataforma Lattes. Bibliotecas. Anales De Investigación, Havana, v. 16, n. 3, p. 207-220. 
NORONHA, Daisy Pires; MARICATO, João de Melo. Estudos métricos da informação: primeiras aproximações. Encontros Bibli, Florianópolis, v. 13, n. 1, p. 116-228, 2008.

OLIVEIRA, Ely Francina Tannuri de; GRACIO, Maria Cláudia Cabrini. Indicadores bibliométricos em ciência da informação: análise dos pesquisadores mais produtivos no tema estudos métricos na base Scopus. Perspectivas em ciência da informação, Belo Horizonte, v. 16, n. 4, p. 16-28, dez. 2011

OTLET, Paul. Traité de documentation: le livre sur le livre. 2. ed. Liège: Centre de lecture publique de la communauté française de Belgique, 1989.

RAMALHO, Francisca Arruda. O uso das novas tecnologias em bibliotecas e serviços de informação. Informação e Sociedade, João Pessoa, v. 3, n. 1, p. 5361, 1993.

SELLTIZ, Claire et al. Métodos de pesquisa das relações sociais. São Paulo: Herder, 1965.

SNBU. In: Repositório FEBAB. FEBAB: São Paulo, 2020.

SOUZA, Rosali Fernandez de; STUMPF, Ida Regina Chitto. Ciência da informação como área do conhecimento: abordagem no contexto da pesquisa e da pós-graduação no Brasil. Perspectivas em ciência da informação, Belo Horizonte, v. 14, n. esp., p. 41-58, 2009.

URBIZAGASTEGUI, Ruben Alvarado; RESTREPO-ARANGO, Cristina. Crescimento da literatura sobre bibliometria, informetria e cientometria no Brasil. Revista Ibero-Americana de Ciência da Informação, Brasília, DF, v. 10, n. 1, p. 6-31, 2017.

VAN ECK, Nees Jan; WALTMAN, Ludo. Visualizing bibliometric networks. In: DING, Ying; ROUSSEAU, Ronald; WOLFRAM, Dietmar (eds.).

Measuring scholarly impact: methods and practice. San Francisco: Springer, 2014. p. 285-320.

VANZ, Samile Andréa de Souza. Redes Colaborativas nos Estudos Métricos de Ciência e Tecnologia. Liinc em Revista, Rio de Janeiro, v. 9, n. 1, p. 171-180, 2013.

DOWNLOAD. In: VOSviewer: visualizing scientific landscapes. Leiden: Universiteit Leiden, 2021.

VAN ECK, Nees Jan; WALTMAN, Ludo. VOSviewer Manual: manual for VOSviewer version 1.6.8. Leiden: Universiteit Leiden, 2018.

VANZ, Samile Andrea de Souza; SANTIN, Dirce Maria; PAVÃO, Caterina Marta Groposo. A bibliometria e as novas atribuições profissionais nas 
bibliotecas universitárias. InCID: Revista de Ciência da Informação e

Documentação, São Paulo, v. 9, n. 1, p. 4-24, 2018.

WITTER, Geraldina; SOUZA, Jamili Salem. British Psychophysiology Society Annual Meeting (2005): análise da produção. Ciência da Informação, Brasília, v. 36, n. 2, p. 85-91, maio/ago. 2007.

ZIMAN, John. Conhecimento público. São Paulo: EDUSP, 1979.

\title{
Trends in research on university libraries: a bibliometric study of the annals of the SNBU
}

\begin{abstract}
Discusses research trends in university libraries through bibliometric analysis of the annals of the National Seminar on University Libraries (SNBU). The research is justified by the need to scale the themes exposed in the largest event on university libraries, which appear for research trends in Brazil. The SNBU annals available on the network in an electronic medium were used as an information source, whose extraction of metadata, the analysis of keywords indexed by the authors in the articles, then standardized according to the specifications of the VOSviewer metric software. It is concluded that the themes most discussed at the seminar are related to emerging technologies in libraries, as well as scientific production and its aspects, involving the issue of communication and the repositories that permeate this process, inferring that university libraries evolve with the advent of information and communication technologies.
\end{abstract}

Keywords: Bibliometrics; University libraries; Thematic analysis; Seminar National of University Libraries

Recebido: $23 / 03 / 2021$

Aceito: 02/06/2021

\section{Declaração de autoria}

Concepção e elaboração do estudo: Célia Regina Simonetti Barbalho, Danielly Oliveira Inomata, Mateus Rebouças Nascimento e Cleiton Mota de Souza.

Coleta de dados: Mateus Rebouças Nascimento.

Análise e interpretação de dados: Cleiton Mota de Souza e Mateus Rebouças Nascimento.

Redação: Célia Regina Simonetti Barbalho, Mateus Rebouças Nascimento Danielly Oliveira Inomata e Cleiton Mota de Souza.

Revisão crítica do manuscrito: Célia Regina Simonetti Barbalho; Danielly Oliveira Inomata e Cleiton Mota de Souza. 
Mateus Rebouças Nascimento, Danielly Oliveira Inomata, Célia Regina Simonetti Barbalho, Cleiton Mota de Souza

\section{Como citar}

NASCIMENTO, Mateus Rebouças; INOMATA, Danielly Oliveira;

BARBALHO, Célia Regina Simonetti; SOUZA, Cleiton Mota de. Tendências em pesquisas sobre bibliotecas universitárias: um estudo bibliométrico dos anais do SNBU. Em Questão, Porto Alegre, v. 28, n. 1, p. 234-257, 2022. DOI: http://dx.doi.org/10.19132/1808-5245281.234-257

${ }^{1}$ Os anais do SNBU estão disponíveis na íntegra no Repositório da Biblioteca Universitária da UFMG (EDIÇÕES ANTERIORES, 2014).

2 As edições de 2016 e 2018 dos anais do SNBU estão disponíveis no Repositório da FEBAB (SNBU, 2020).

${ }^{3} \mathrm{O}$ software Vosviewer tem com objetivo construir redes métricas por meio da extração de dados, disponibilizado gratuitamente para download (DOWNLOAD, 2021).

${ }^{4}$ Manual explicativo sobre o software Vosviewer elaborado por Nees Jan Van Eck e Ludo Waltman (2018) apresentando como extrair informações de bases de dados. 